\title{
Effects of Humidified Enriched Air on Combustion and Emissions of a Diesel Engine
}

\author{
Carlo Pirola ${ }^{1}$, Federico Galli ${ }^{1}$, Carlo A. Rinaldini ${ }^{2 *}$, Flavio Manenti ${ }^{3}$, Massimo Milani ${ }^{4}$, Luca Montorsi ${ }^{4}$ \\ ${ }^{1}$ Università degli Studi di Milano, Dipartimento di Chimica, Milano, Italy \\ ${ }^{2}$ Università di Modena e Reggio Emilia, Dipartimento Ingegneria "Enzo Ferrari", Modena, Italy \\ ${ }^{3}$ Politecnico di Milano, Dipartimento di Chimica, Materiali e Ingegneria Chimica "Giulio Natta", Milano, Italy \\ ${ }^{4}$ Università di Modena e Reggio Emilia, Dipartimento di Scienze e Metodi per l'Ingegneria, Reggio Emilia, Italy \\ *Corresponding author: carloalberto.rinaldini@unimore.it
}

\begin{abstract}
The potential of Humidified Enriched Air (HEA) on Diesel engine combustion is investigated, by means of 3D CFD combustion simulations, on a current production 4-cylinder turbocharged Diesel engine. HEA is supposed to be obtained by water degassing operation, exploiting the different vapor-liquid equilibria of it main constituents, nitrogen and oxygen. Simulations are carried out using a customized version of the KIVA $3 \mathrm{~V}$ code, featuring a detailed chemistry combustion mechanism. The model of the engine is previously validated through comparison with experimental data and then it is used to analyse combustion and emissions of HEA combustion in combination with late injection strategies. Numerical results demonstrate that oxygen-enriched air enhances the thermal efficiency of the engine (up to 13\%) and reduces significantly soot emissions; on the other hand, in-cylinder peak pressure and NOx emissions increase. The latter can be significantly reduced by using humidified air maintaining the advantage in terms of thermal efficiency and in soot reduction, nevertheless the baseline case NOx emissions cannot be restored.
\end{abstract}

Keywords: Humidified Enriched Air; water degassing; Diesel engine; emissions; CFD

\section{Introduction}

Atmospheric dry air is composed by about $78 \%$ of nitrogen and about $21 \%$ of oxygen in volume with little amount of other gasses, mainly argon and carbon dioxide. Oxygen enriched air (EA) is the corresponding gas mixture with a higher content of oxygen, in the range $22-35 \%$. This mixture is already used in industrial plants, in particular for oxidation reactions. Moreover, EA is also sell as market product, for example for health treatments or in scuba tanks.

Enriched air mixture in industrial chemical plants is currently produced by mixing a stream of pure oxygen with a stream of atmospheric air [1]. Pure oxygen is produced by the air cryogenic separation [2] and, as possible alternative in particular for smaller processes, by membrane separation [3]. The energy demand for the oxygen production is intensive for both these technologies, and consequently for the achievement of enriched air production. Moreover, it is important to consider that the implementation of oxygen enrichment needs investments for a suitable oxygen supply system, with a devoted control unit for the oxygen injector, in order to assure reliable and safe operation procedures.

A new technology was recently proposed and investigated for the production of EA by simple water degassing, by theoretical considerations and experimental runs [4]. Preliminary process simulations and cost-analysis have been performed with positive feedbacks [5]. Moreover, the same technology has been evaluated from an environmental point of view and the eco-economical prospective, by applying the life cycle assessment methodology (LCA) [6]. Water can be considered as renewable by definition and new technologies based on its use are emerging [7] [8]. For this reason this process driven by water utilization should be appealing as a renewable improvement of energy sources exploitation. In this new process, EA is produced by desorption from water previously equilibrated with atmospheric air. In fact, due to the higher oxygen solubility in water compared to the nitrogen one, since the vapor liquid equilibria of these two gases are strongly different respect air [9], the relative composition of nitrogen and oxygen in water is different respect atmospheric air. More in detail, oxygen dissolves in water 22-35\% more respect nitrogen, depending on the temperature and pressure of the system. The main drawback of this new technology is represented by the little amount of oxygen and nitrogen solubilized in water. This is clearly connected with the need of high quantity of water required for final applications. Nevertheless, it should be possible to overcome this potential limitation by using a pressurized tank, before the degassing process, for the equilibration of atmospheric air and water. In this configuration, water and air are put into contact at high pressure by increasing in this way the content of solubilized gases. Consequently, the water exiting from the equilibration tank can be degassed by decreasing the pressure. It will be possible to degas water equilibrated with air at room pressure, or under different pressures depending on the on the amount of EA required in the process. Moreover, in order to optimize the water use, this same liquid after its degassing can be further recycled getting it in contact with new atmospheric air [10].

The use of enriched air, as alternative oxidizing agent in Diesel engines, is well known to be beneficial [11][12]. In fact, EA promoted combustion is considered as one of the most interesting technologies to improve the performance in Diesel engines and to simultaneously reduce pollution. By using EA as oxidizer, the most important advantage is the decrease in soot emissions and fuel consumption. The application of EA in internal combustion engines has intuitively a tremendous potential as considering the number of engines in the world, also a very little advantage can lead to very important results. This approach addressed to the advantages obtainable through the optimization of the oxidising mixture can be complementary to what has already been studied for the fuel mixture. For example Reşit Seraç et al. [13] evaluated the effects of alternative fuel types on combustion, performance and emissions based on some biodiesel fuel 
blends. Other parameters can be taken into account to improve the performance, combustion and emissions characteristics of combustion engine, as the compression ratio [14] or the combustion chamber configuration [15].

The application of EA to internal combustion engines can be proposed for both road vehicles with the implementation of a water vessel or, most promising, for ship engines for which the availability of water is actually endless. The potential of EA in Diesel engines was already considered by the Authors by a preliminary study [16], analysing the effects of oxygen enriched air on the exhaust emissions and performance of a high-speed direct-injection Diesel engine, by means of 3D Computational Fluid Dynamics (CFD) simulations. The numerical approach has been selected since up-to-date CFD software are able to provide realistic simulations and reliable results of complex phenomena with costs that are very low in comparison with experiments in many engineering fields [17] [18] [19].

The preliminary CFD simulations demonstrated that EA mixture allows to increase engine thermal efficiency up to $8 \%$, thanks to a faster and more complete combustion, and drastically reduces soot emissions. The increase of in-cylinder peak pressure and the rise of $\mathrm{NO}_{\mathrm{x}}$ emissions were the main drawbacks of this technology. This preliminary study was conducted considering, as first hypothesis, EA mixture formed only by nitrogen and oxygen. Actually, the content of water inside this mixture should be considered. The presence of humidity can influence the results. Moreover, water is clearly present in the EA mixture due to the production process [10].

For this reason the present paper aims to quantify the humidity present in the humidified enriched air (HEA) mixture produced depending on the different working parameters (pressure and temperature the most important) and to correlate the content of water with the engine performance and emissions. In fact, combustion air humidification is a well-known technic for $\mathrm{NO}_{\mathrm{x}}$ reduction in an internal combustion engine [12] [20] [21], but, in the case of HEA produced by water degassing, there is a further advantage: after the degassing phase, EA has a very high water content and therefore a water injection system is not needed. The paper presents the results of $3 \mathrm{D}$ combustion simulations on a Diesel engine in which the combustion air humidification is applied in order to reduce the negative effect of EA on $\mathrm{NO}_{\mathrm{x}}$ emissions and results are compared with the results obtained from delaying the injection profile.

\section{Humidified Enriched Air (HEA) Production}

Water in equilibrium with atmospheric air contains different amounts of dissolved $\mathrm{O}_{2}$ and $\mathrm{N}_{2}$. The quantities of these gases inside water are strongly dependent on the temperature and pressure of the system. In particular, the use of high pressures can increase the dissolved gases in water. For this reason, a system based on a pressurized tank in which water and air are put in contact is the most convenient system to exploit this principle. The exiting water, rich of dissolved gas, can be then set at lower pressure, by achieving degassing process, and wet EA consequently produced.

The amount of water present in the degassed enriched air can be calculated by simulation software, based on the thermodynamic approach previously validated [10]. The selected thermodynamic model was UNIQUAC to take into account the non ideality of the system by the calculation of activity coefficients, and vapor liquid equilibria of oxygen, nitrogen and water were determined according to the paper of Manenti and Pirola [5]. The proposed flowsheet has been simulated by the simulation plant software PRO/II by AVEVA.

On the basis of an economical optimization [10], the most convenient configuration of the EA production plant by pressurized tank and consequent degassing operation was based on a pressurized saturation pressure of 30 bar and a degassing tank at 1 bar. Both these are at room temperature to achieve the lowest price for EA. The concentration of water in the enriched air so produced results 0.0419 as molar fraction, i.e. moles of water respect the total number of moles.

It is possible to investigate the influence of different experimental parameters on water concentration. The water concentration in the enriched air stream is mainly influenced by temperature and pressure of the degassing tank, as reported in Fig. 1 and Fig. 2.
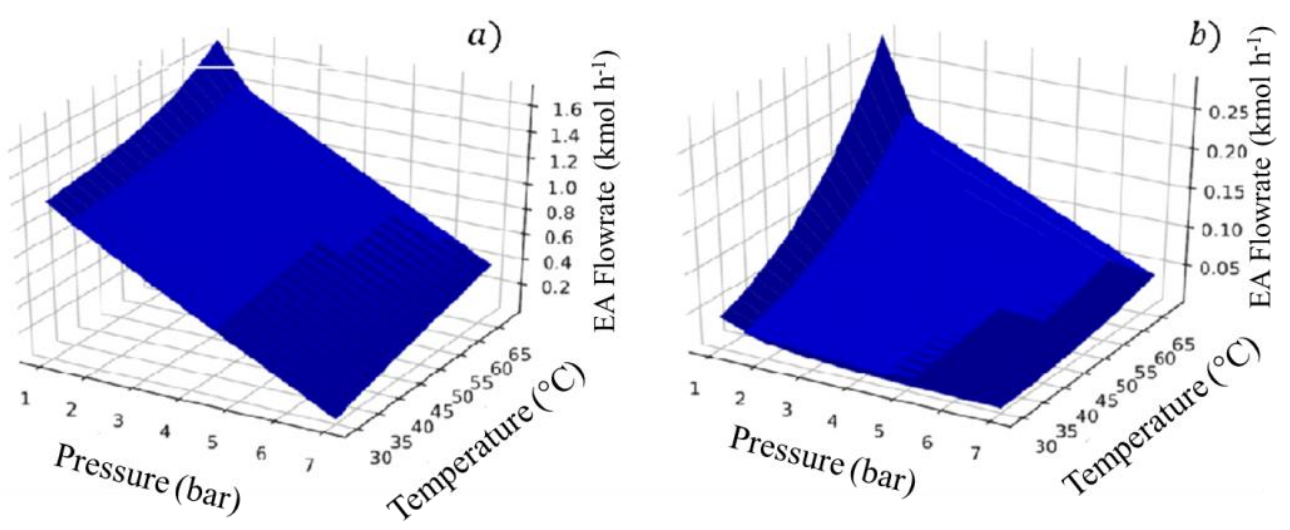

Figure 1: a) EA flowrate $\left(\mathrm{kmol} \mathrm{h}^{-1}\right)$ and b) water molar fraction vs. degassing tank temperature and pressure. Water flowrate in the saturation tank: $5000 \mathrm{~kg} \mathrm{~h}-1$; air flowrate in the saturation tank: $30 \mathrm{~m}^{3} \mathrm{~h}^{-1}$. 

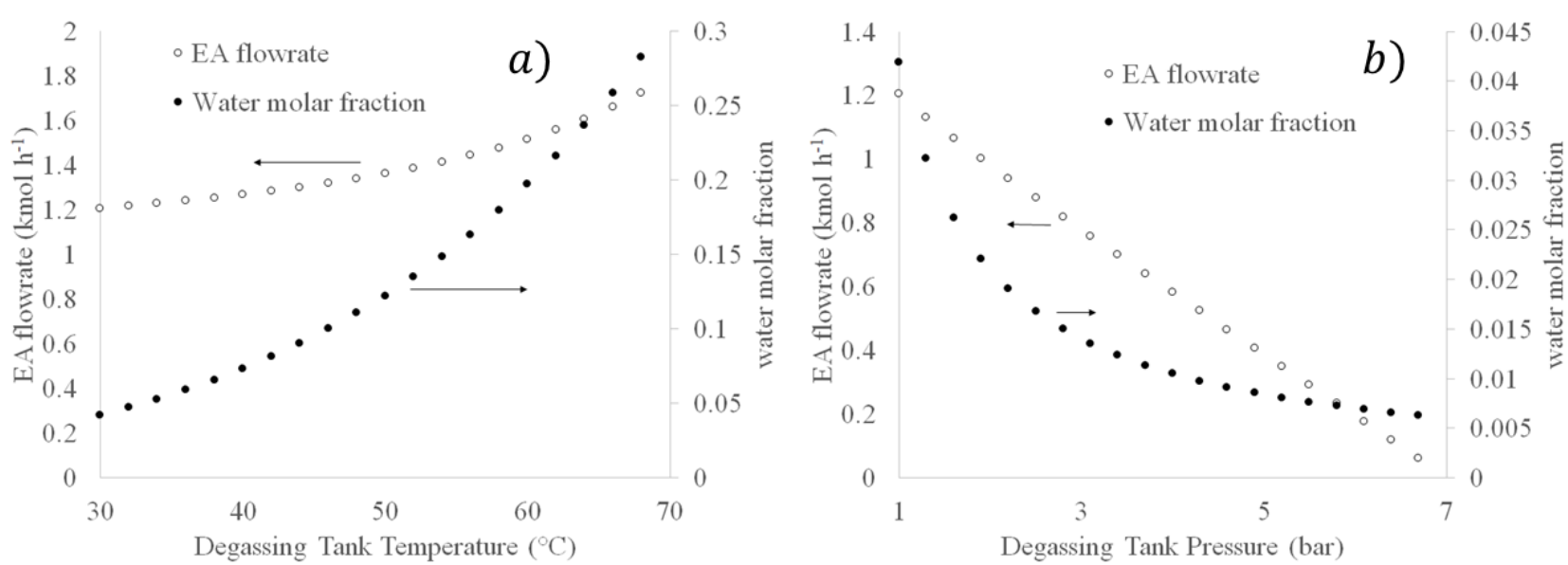

Figure 2: EA flowrate $\left(\mathrm{kmol} \mathrm{h}^{-1}\right)$ and water molar fraction vs. degassing a) tank temperature with fixed degas pressure $=1$ atm and b) pressure with fixed degas temperature $=30^{\circ} \mathrm{C}$. Water flowrate in the saturation tank: $5000 \mathrm{~kg} \mathrm{~h}^{-1}$; air flowrate in the saturation tank: $30 \mathrm{~m}^{3} \mathrm{~h}^{-1}$

It is possible to change the humidity in the exiting stream of HEA by applying different temperature and pressure in the degassing tank, as shown in figures 1 and 2. Water content in fact is dependent from its vapor pressure and then increases for higher temperature and lower pressure. The change of operative parameters obviously influences the EA flowrate too. A higher temperature increases the gas release while a higher pressure decreases EA production rate. The concentration of oxygen in only little influenced by $\mathrm{T}$ and $\mathrm{P}$ in the considered range.

\section{Engine Modelling}

The engine used for the study is a series turbocharged Diesel engine, manufactured by FCA. It is characterized by four in-line cylinders a total displacement of $1247 \mathrm{cc}$ and four valves per cylinder. The fuel injection systems includes a high-pressure common-rail and four six-hole electro-injectors. The main features of the engine are listed in Table 1.

Table 1. Main engine parameters

\begin{tabular}{llll}
\hline Total displacement & $1247 \mathrm{cc}$ & Number of valves & 4 per cyl \\
\hline Bore x stroke & $69.6 \times 82.0 \mathrm{~mm}$ & Intake valve closing & $33.0^{\circ} \mathrm{ABDC}^{*}$ \\
\hline Connecting rod & $131.3 \mathrm{~mm}$ & Exhaust valve opening & $67.6^{\circ} \mathrm{BBDC}^{* *}$ \\
\hline Compression ratio & $17.6: 1$ & Injector hole diameter & $0.121 \mathrm{~mm}$ \\
\hline \multicolumn{2}{c}{ * After Bottom Death Center } & ** Before Bottom Death Center \\
\hline
\end{tabular}

For the combustion simulations, a customized version of the KIVA-3V code has been used [22]. KIVA 3V is a Fortran program that solves the conservation equations for evaporating fuel sprays, coupled with the 3-Dimensional Computational Fluid Dynamics (3D-CFD) of compressible, multi-component, reactive gases in an engine cylinder with arbitrarily-shaped piston geometry. Turbulence is accounted for by means of the k-epsilon model, while for heat transfer the standard Launder and Spalding approach is followed. The version of the KIVA-3V code used in this study also includes: the Kelvin-Helmholtz/Rayleigh-Taylor (KHRT) model for fuel spray atomization [20], a detailed combustion chemistry approach [21], the PaSR (Partially Stirred Reactor) model for the turbulence-chemistry interaction [21] and a Diesel Oil Surrogate (DOS) [22].

The DOS model simulates the multi-component nature of the fuel vapor, regardless that the fuel is assumed to be the one-component substance. Since the properties of real diesel oil are compiled in the DI model of the KIVA-3V fuel library, the information was used in the modelling, and only the specified chemical formula of the fuel was selected as $\mathrm{C} 14 \mathrm{H} 28$. However, since the oxidation paths for real diesel oil are not known, fuel is assumed to be decomposed into the constituent components; $70 \%$ n-heptane $(\mathrm{C} 7 \mathrm{H} 16)$ and $30 \%$ toluene $(\mathrm{C} 7 \mathrm{H} 8)$, through a global pyrolysis. Then, the oxidation sub-mechanisms for the constituent components is calculated with a detailed chemical mechanism consisting of 72 species participating in 306 kinetic stages. The aliphatic component, $n$-heptane, was chosen to be in excess, since its Cetane number is 56, which is similar to the Cetane number of real diesel oil. The modified model is able to predicts the ignition properties of the constituent components in a good agreement with experimental data as reported in [22].

As far as the pollutant emissions formation, the kinetics of aromatics till gaseous soot precursors supposed to be acenaphthylene are integrated into the combustion chemistry and the extended Zeldovich mechanism is applied to accurately predict NO formation.

Validation results of the customized KIVA-3V code for different current production Diesel engines demonstrated a good agreement between calculations and experiments, as reported in [23][24][25].

Before application in EA combustion analysis, a 3D model of the engine was built and validated by comparison with a set of experimental data in terms of engine performance, indicated quantities, and pollutant emissions. The comparison was carried out on 4 different operating points featuring 4 different rotational speeds, each time at full load. The 
computational grid for combustion simulations, shown in Figure 3, is a $60^{\circ}$ sector grid in order to exploit the axialsymmetry of the combustion chamber; the grid consists of about 70,000 cells at Top Dead Centre (TDC). KIVA combustion simulations were carried out from Intake Valve Closing (IVC) to Exhaust Valve Opening (EVO) and previous CFD 3D simulations provided the simulation initial conditions such as pressure, temperature, flow-field and gas composition. In particular, as far as the initial flow field is concerned, velocities were calculated with a Bessel function swirl profile, which intensity is set in order to reproduce the angular momentum calculated through the intake stroke simulations. Finally, experimental measurements provided the injection rate and the fuel temperature for the 4 investigated operating points.

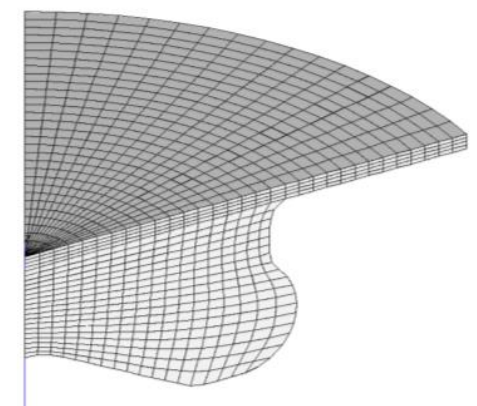

Figure 3: Computational mesh at Top Dead Center (TDC)

In Figure 4, a comparison between simulations and experimental data is shown in terms of mean in-cylinder variables and engine emissions; in particular, engine performance are represented by the Gross Indicated Mean Effective Pressure (IMEP*: Indicated Mean Effective Pressure calculated between IVC and EVO) and the most relevant emissions for Diesel engine are reported (NOx and soot). The comparison in term of in-cylinder pressure and Rate of Heat Released (RoHR) is reported in Figure 5. Both Figure 4 and 5 illustrate a good agreement between calculated and measured data for all the simulated operating points. It is important to note that, as far as emissions prediction is concerned, a specific tuning has been required to get a reasonable agreement in terms of absolute values. In particular, for soot analysis, since the oxidation reactions are supposed to be in the gas phase, the predicted concentrations have to be multiplied by one empirical coefficient, determined by matching the experimental values [23]. More details of the engine model and its validation through comparison with experiments are reported in [16] [23].

a)

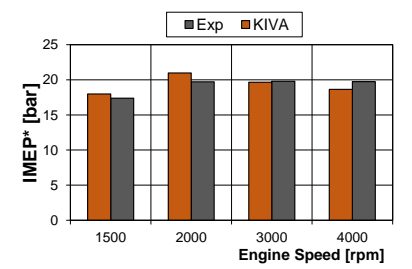

b)

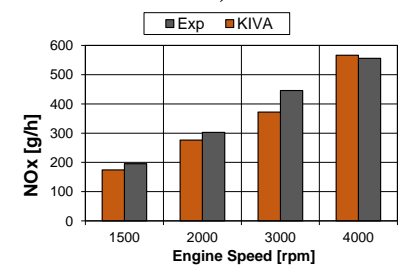

c)

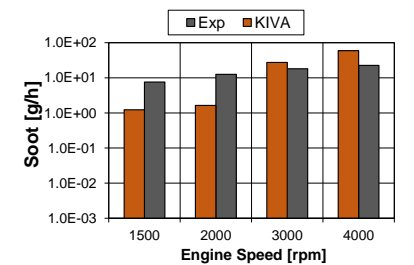

Figure 4: comparison between simulations and experiments in terms of Gross Indicated Mean Effective Pressure (a), NOx (b) and soot emissions (c)

a)

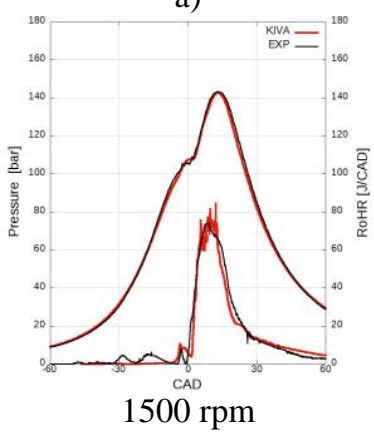

b)

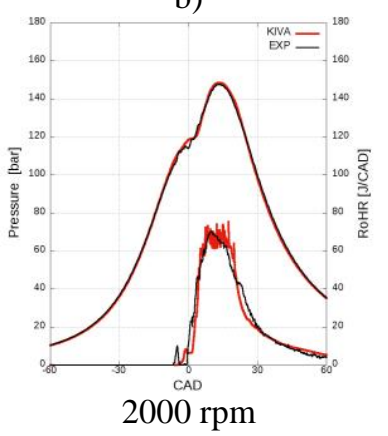

c)

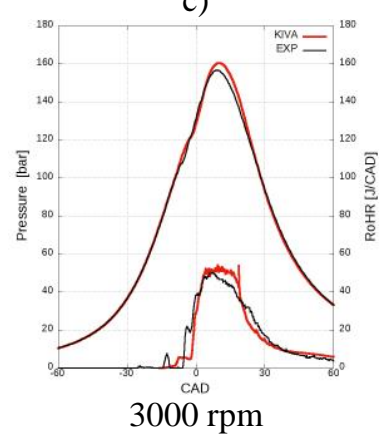

d)

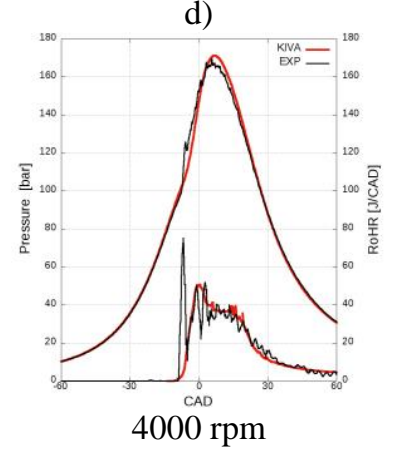

Figure 5: comparison between simulations and experiments in terms of in-cylinder pressure and Rate of Heat Release at different rotational speed

\section{Results and Discussion}

Simulations with HEA were carried out at full load, $2000 \mathrm{rpm}$. In this operating point the injection law consists of 2 separate pulses: 1) a pilot injection at about 8 cad BTDC; 2) the main injection at about 4 cad BTDC. The total amount 
of fuel injected in one stroke is $41.8 \mathrm{mg}$. For this operating point, 4 EA Oxygen levels were investigated: the oxygen level was varied between $21 \%$ to $36 \%$ with a step of $5 \%$.

Figure 6 shows the effect of EA on combustion and engine performance. It can be noticed that, with enriched air, the Rate of Heat Release (RoHR) increases in the first phase of combustion revealing that the higher levels of oxygen promotes a faster combustion; as a consequence peak in-cylinder pressure and temperature rise, producing, along with the presence of higher concentration of oxygen, an increase of engine efficiency and NOx emissions. The main advantages in terms of engine efficiency increment can be obtained with an oxygen level of $26 \%(+9 \%)$ and $31 \%$ $(+13 \%)$, while further increments in oxygen level do not seem to lead to additional benefits. Figure 5 shows also that EA is very effective in soot reduction: even with an oxygen level of $26 \%$ soot is almost eliminated in comparison with standard air ( $21 \%$ of oxygen). These results can be explained considering that soot emissions are directly correlated to local oxygen/fuel ratio that increases with EA, but a higher oxygen concentration, along with higher temperature, also produces a rise in NOx emissions.

a)

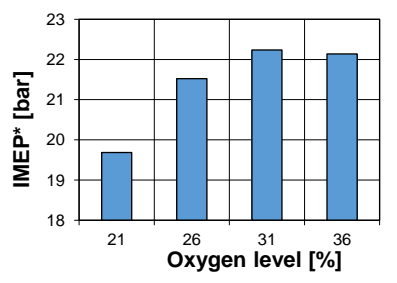

d)

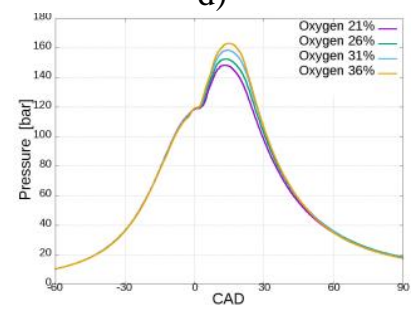

b)

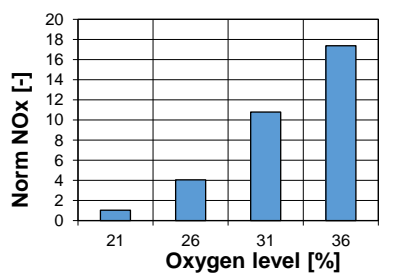

e)

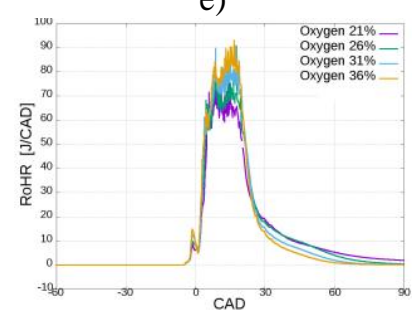

c)

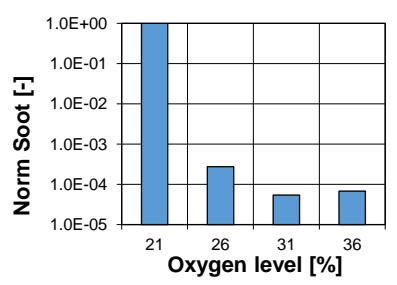

f)

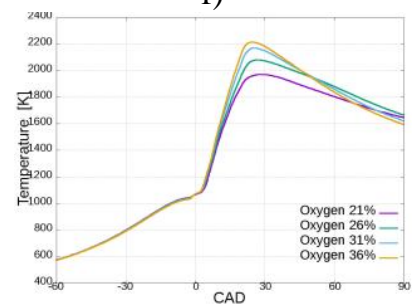

Figure 6: effects of EA on: Gross IMEP (a), NOx (b) and Soot emissions (c) (normalized with reference to base case (21\%)), incylinder pressure (d), Rate of Heat Release (e) and Temperature (f)

In order to limit the negative effects of EA on in-cylinder pressure and NOx emissions, two different strategies were tested: injection delaying and combustion air humidification. In details, 5 Humidity Ratio (HR) and 4 injection strategies were investigated considering 2 different oxygen levels: $21 \%$ (standard air) and $31 \%$. The relative humidity of combustion air (HR) was varied from $0 \%$ to $100 \%$ (step 25\%) and the original injection law (label " 0 " in the plots) was delayed by 2, 4 and 6 crank angle degrees. The results of the simulation runs were then processed, producing the results reported in figures 7 (cycle mean values) and 8 (indicated quantities).

a)

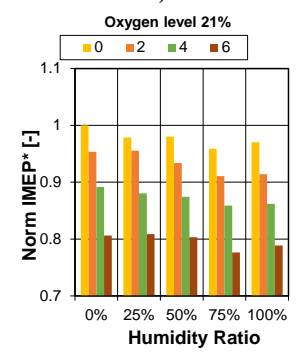

e)

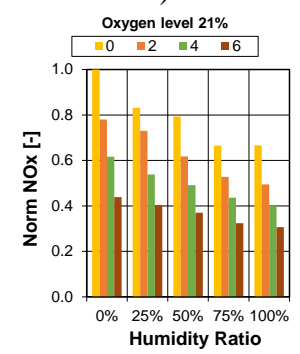

b)

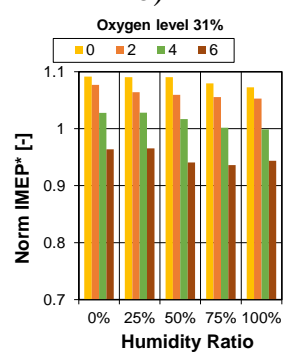

f)

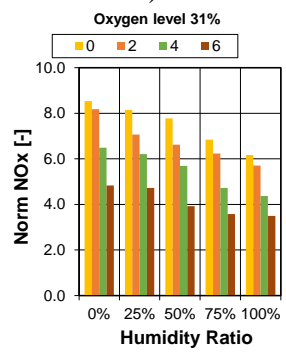

c)

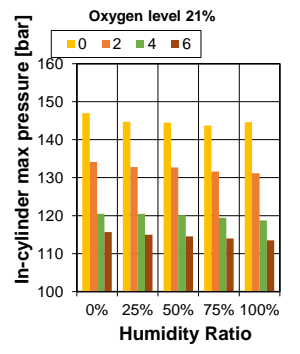

g)

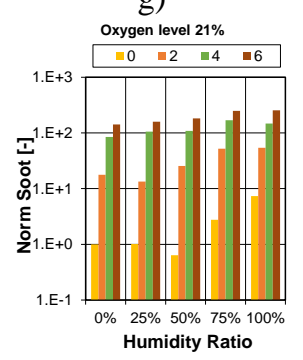

d)

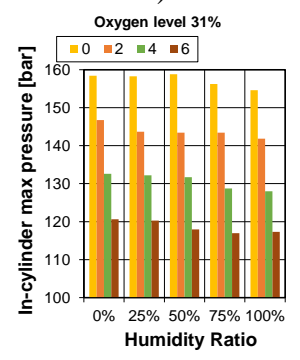

h)

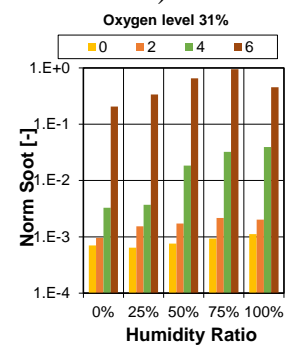

Figure 7: Influence of injection timing and combustion air humidification on engine performance and emissions 
Evaluating the effects of the injection profile, it can be notice that, as expected, delaying injection retards the combustion phase with a positive effect on in-cylinder peak pressure reduction; on the other hand, it causes a decrease of IMEP and, consequentially, a decrease of engine performance and efficiency. However, it is interesting to note that an injection delay of only 2 cad is enough to limit the in-cylinder pressure to the values of the base case (about 150 bar) without losing the advantage of EA combustion in terms of IMEP increment (+8\% of IMEP for the base case (HR $0 \%)$ passing from standard air to EA 31\%). Injection delaying also leads to a reduction of in-cylinder temperature and, as a consequence, a decrease in NOx emissions even if the NOx levels of EA are always higher than those of the base case. Combustion retardation and lower temperatures obtained with injection delays also produce an increment of soot emissions, but also in this case the advantage obtained with EA combustion is not lost if the injection delay is limited to 2 or 4 crank angle degrees.

Considering combustion air humidification, Figures 7 and 8 show that it has a very small influence on combustion development: the RoHR is almost identical passing from $0 \%$ to $100 \%$ of humidity ratio, while in-cylinder pressure and temperature decrease very slowly as the HR increases. Combustion air humidification has a small influence also on engine performance and efficiency (IMEP is reduced of 2-3\% from RH $0 \%$ to RH 100\%). The influence of air humidification is much more evident on engine emissions: Figure 7 shows that as HR increases, NOx emissions are reduced and soot increases. On this last point it is however interesting to observe that air humidification seems to have better effects on emissions in comparison with late injections: NOx reduction is comparable with the 2 technologies, while soot rise is much more relevant with late injection. Referring to the base case (oxygen level 21\%) combustion air humidification allows a NOx reduction up to $30 \%$ with a slight decrease of IMEP; moreover, soot emissions are just slightly affected by air humiliation up to $\mathrm{RH}=50 \%$ while the NOx reduction reaches $20 \%$.

Figure from A-1 to A-4 in the appendix show some pictorial view of the combustion chamber during combustion: oxygen concentration and temperature are plotted on 2 different cutplanes, one passing through the cylinder axis and the centre of the injector hole and the other perpendicular to the former and always passing through the centre of the injector hole. From this pictures, the advantage is evident in terms of oxygen concentration of EA combustion as well as the higher temperatures reached when oxygen increases. Moreover, looking at temperature distribution at TDC, the faster combustion development obtained with EA is visible. It can also be noticed that air humidification is able to slightly reduce local peak temperature inside the combustion chamber explaining the NOx reduction that was observed.

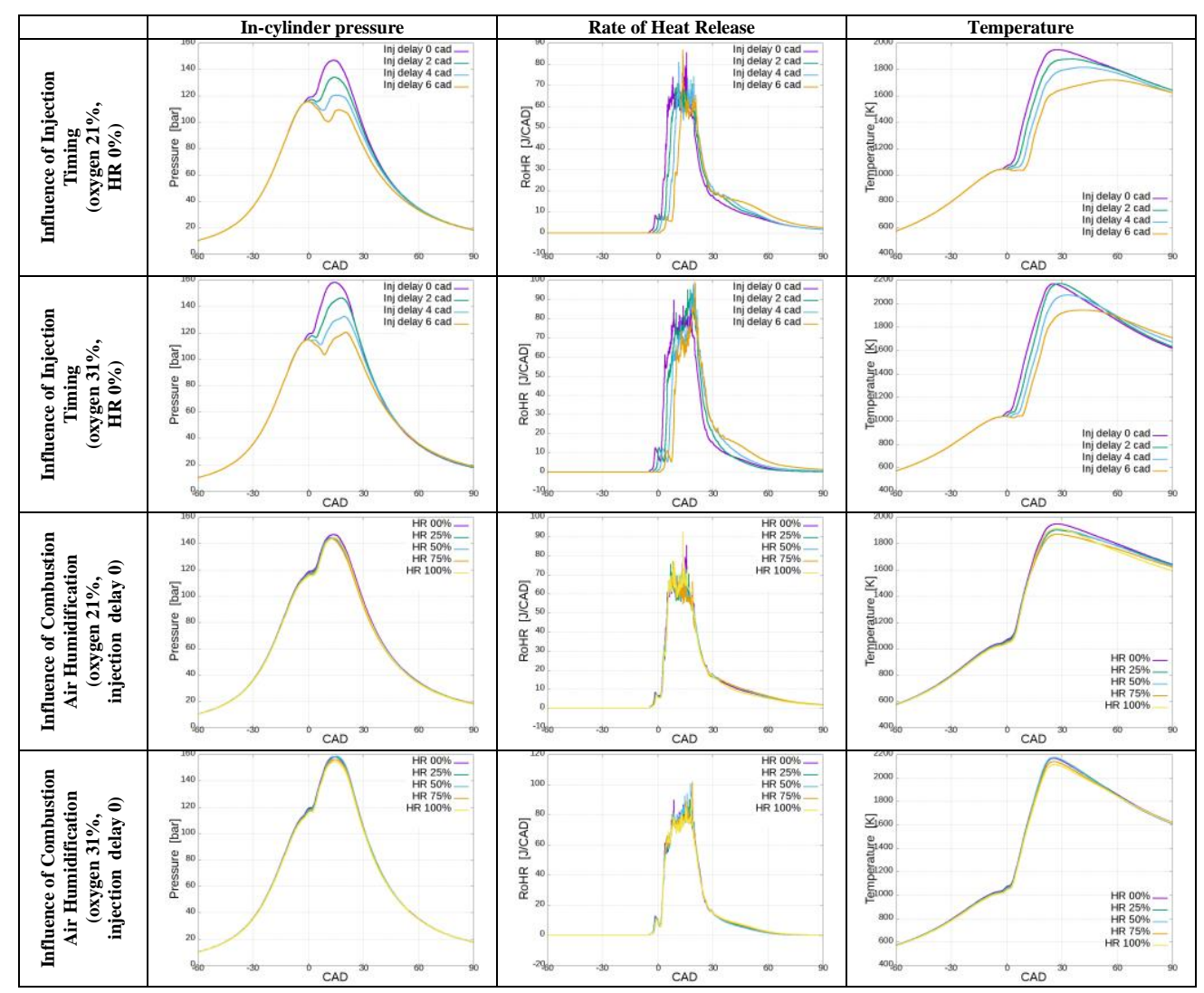

Figure 8: Influence of injection timing (first and second rows, for 2 different oxygen levels) and combustion air humidification (third and fourth rows, for different oxygen levels) on in-cylinder pressure and temperature and Rate of Rate Release

Finally, in order to assess the benefit of combustion air humidification coupled with oxygen air enrichment, the results of 3 different operating points are compared:

- B0 (oxygen level $21 \%$, humidity ratio $0 \%$, injection delay 0 cad)

- H1 (oxygen level 31\%, humidity ratio 100\%, injection delay 2 cad)

- D2 (oxygen level $31 \%$, humidity ratio $0 \%$, injection delay 4 cad) 
Figure 9 reports simulation results for the selected operating points. It is possible to notice that the soot is close to zero for the 2 operating conditions that use EA (i.e. H1 and D1), on the other hand higher NOx values can be found for both of them. The results for points $\mathrm{H} 1$ and D2 prove that that the optimal solution in terms of emissions is obtained by combining the combustion air humidification and the injection delay: the soot and NOx emission for the operating condition $\mathrm{H} 1$ are slightly lower than D2 operation, while the in-cylinder peak pressure is approximately the same as B0 with an IMEP value $5 \%$ higher than the base case.

a)

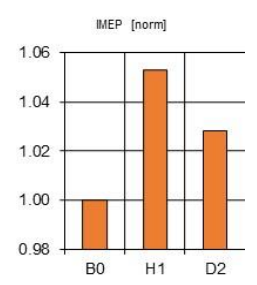

b)

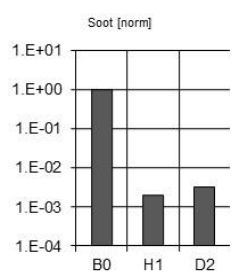

c)

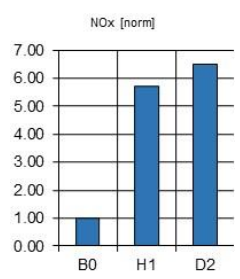

d)

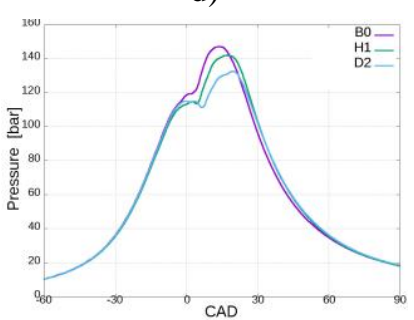

e)

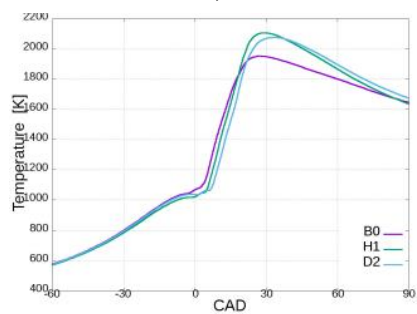

Figure 9: Comparison between 3 different operating points: B0 (red line in chart), H1 (green line in chart) and D2 (blue line in chart) in terms of Gross IMEP (a), soot (b) and NOx (c) emissions, in-cylinder pressure (d) and temperature (e)

\section{Conclusion}

The paper presents a numerical investigation on combustion and emissions of a light duty turbocharged Diesel engine using Humidified Enriched Air. The analysis was carried out on an engine model, validated through experiments, by means of 3D CFD simulations focused on the combustion process.

It was found that oxygen-enriched air may increase the engine efficiency (up to 13\%) and significantly reduce soot emissions thanks to a faster and more complete combustion but it also increases in-cylinder peak pressure and NOx emissions. Both injection delaying and air humidification seem to be useful strategies to limit the drawback of EA combustion even if air humidification appears more advisable in order to obtain the best compromise between soot and NOx emissions. The best result ( $+5 \%$ thermal efficiency, soot almost eliminated, limited increment of NOx, same peak pressure of base case) is obtained using EA (oxygen level 31\%) and a combination of combustion air humidification (Humidity Ratio 100\%) and injection postponing (2 cad of delay).

\section{Acknowledgments}

The work was partially financed by the project "Enriched Air POWERed Chemical Plants and Combustion Engines: EAPOWER" in the call "Azione A, Piano sostegno alla ricerca - anno 2018" by Dipartimento di Chimica, Università degli Studi di Milano.

\section{References}

[1] R.H. J., H.D. Obermeyer, B. Schreiner, S. Wolf, Oxygen Enrichment for intensification of air oxidations reactions, 2015.

[2] B. Belaissaoui, Y. Le Moullec, H. Hagi, E. Favre, Energy Efficiency of Oxygen Enriched Air Production Technologies: Cryogeny vs Membranes, Energy Procedia. 63 (2014) 497-503. https://doi.org/10.1016/j.egypro.2014.11.054.

[3] P. Bernardo, E. Drioli, G. Golemme, Membrane Gas Separation: A Review/State of the Art, Ind. Eng. Chem. Res. 48 (2009) 4638-4663. https://doi.org/10.1021/ie8019032.

[4] F. Manenti, C. Pirola, Process intensification using energy-free highly enriched air: Application to seawater desalination plants, Chem. Eng. Process. Process Intensif. 79 (2014) 40-47. https://doi.org/10.1016/j.cep.2014.03.008.

[5] F. Galli, A. Comazzi, D. Previtali, F. Manenti, G. Bozzano, C.L. Bianchi, C. Pirola, Production of oxygenenriched air via desorption from water: Experimental data, simulations and economic assessment, Comput. Chem. Eng. 102 (2017) 11-16. https://doi.org/10.1016/j.compchemeng.2016.07.031.

[6] F. Galli, C. Pirola, D. Previtali, F. Manenti, C.L. Bianchi, Eco design LCA of an innovative lab scale plant for the production of oxygen-enriched air. Comparison between economic and environmental assessment, J. Clean. Prod. 171 (2018) 147-152. https://doi.org/10.1016/j.jclepro.2017.09.268.

[7] A. Roberts, B. Thomas, P. Sewell, E. Hoare, Generating renewable power from water hammer pressure surges, Renew. Energy. 134 (2019) 1392-1399. https://doi.org/10.1016/j.renene.2018.09.006. 
[8] F. Ochs, A. Dahash, A. Tosatto, M. Bianchi Janetti, Techno-economic planning and construction of costeffective large-scale hot water thermal energy storage for Renewable District heating systems, Renew. Energy. 150 (2020) 1165-1177. https://doi.org/10.1016/j.renene.2019.11.017.

[9] D.W. Green, R.H. Perry, Perry’s Chemical Engineers'Handbook, 8th ed., McGraw-Hill, 2007.

[10] F. Galli, D. Previtali, G. Bozzano, C.L. Bianchi, F. Manenti, C. Pirola, Production and application of O2 enriched air produced by fresh and salt water desorption in chemical plants, J. Environ. Manage. 217 (2018) 621-628. https://doi.org/10.1016/j.jenvman.2018.03.133.

[11] P. Baskar, A. Senthilkumar, Effects of oxygen enriched combustion on pollution and performance characteristics of a diesel engine, Eng. Sci. Technol. an Int. J. 19 (2016) 438-443. https://doi.org/10.1016/j.jestch.2015.08.011.

[12] K. Cacua, A. Amell, F. Cadavid, Effects of oxygen enriched air on the operation and performance of a dieselbiogas dual fuel engine, Biomass and Bioenergy. 45 (2012) 159-167. https://doi.org/10.1016/j.biombioe.2012.06.003.

[13] M.R. Seraç, S. Aydın, A. Yılmaz, S. Şevik, Evaluation of comparative combustion, performance, and emission of soybean-based alternative biodiesel fuel blends in a CI engine, Renew. Energy. 148 (2020) 1065-1073. https://doi.org/10.1016/j.renene.2019.10.090.

[14] M. Hawi, A. Elwardany, S. Ookawara, M. Ahmed, Effect of compression ratio on performance, combustion and emissions characteristics of compression ignition engine fueled with jojoba methyl ester, Renew. Energy. 141 (2019) 632-645. https://doi.org/10.1016/j.renene.2019.04.041.

[15] S. Khan, R. Panua, P.K. Bose, The impact of combustion chamber configuration on combustion and emissions of a single cylinder diesel engine fuelled with soybean methyl ester blends with diesel, Renew. Energy. 143 (2019) 335-351. https://doi.org/10.1016/j.renene.2019.04.162.

[16] F. Manenti, M. Milani, L. Montorsi, F. Paltrinieri, C. Pirola, C.A. Rinaldini, Performance and Exhaust Emissions Analysis of a Diesel Engine Using Oxygen-Enriched Air, in: 2018. https://doi.org/10.4271/2018-011785.

[17] M. Knoll, H. Gerhardter, R. Prieler, C. Hochenauer, P. Tomazic, H. Schröttner, Effects on numerical calculations of in-flight particle trajectories and temperatures considering multiple particle size and shape, Int. J. Thermofluids. (2020) 100021. https://doi.org/10.1016/j.ijft.2020.100021.

[18] H. Jouhara, B. Fadhl, L.C. Wrobel, Three-dimensional CFD simulation of geyser boiling in a two-phase closed thermosyphon, Int. J. Hydrogen Energy. 41 (2016) 16463-16476. https://doi.org/10.1016/j.ijhydene.2016.02.038.

[19] A. Asadi, Y. Zhang, H. Mohammadi, H. Khorand, Z. Rui, M.H. Doranehgard, M.V. Bozorg, Combustion and emission characteristics of biomass derived biofuel, premixed in a diesel engine: A CFD study, Renew. Energy. 138 (2019) 79-89. https://doi.org/10.1016/j.renene.2019.01.069.

[20] H.-K. Park, S.-H. Ghal, H.-C. Park, S.-W. Choi, S.-H. Kim, A Study on NO x Reduction of Marine 4-Stroke Diesel Engine Using Charge Air Humidification, in: 2011. https://doi.org/10.4271/2011-24-0172.

[21] H.R. Rahai, E. Shamloo, J.R. Bonifacio, Investigation of the Effect of a Humid Air System on Diesel NOx and PM Emissions of a Small Diesel Engine, in: 2011. https://doi.org/10.4271/2011-01-0692.

[22] A.A. Amsden, KIVA-3V: A Block-structured KIVA Program for Engines with Vertical or Canted Valves, LA13313-MS. (1997).

[23] V.I. Golovitchev, L. Montorsi, C.A. Rinaldini, A. Rosetti, CFD Combustion and Emission Formation Modeling for a HSDI Diesel Engine Using Detailed Chemistry, in: ASME 2006 Intern. Combust. Engine Div. Fall Tech. Conf., ASME, 2006: pp. 349-358. https://doi.org/10.1115/ICEF2006-1506.

[24] E. Mattarelli, C.A. Rinaldini, M. Wilksch, 2-Stroke High Speed Diesel Engines for Light Aircraft, SAE Int. J. Engines. 4 (2011) 2011-24-0089. https://doi.org/10.4271/2011-24-0089.

[25] C.A. Rinaldini, E. Mattarelli, V.I. Golovitchev, Potential of the Miller cycle on a HSDI diesel automotive engine, Appl. Energy. 112 (2013) 102-119. https://doi.org/10.1016/j.apenergy.2013.05.056. 


\section{Appendix}

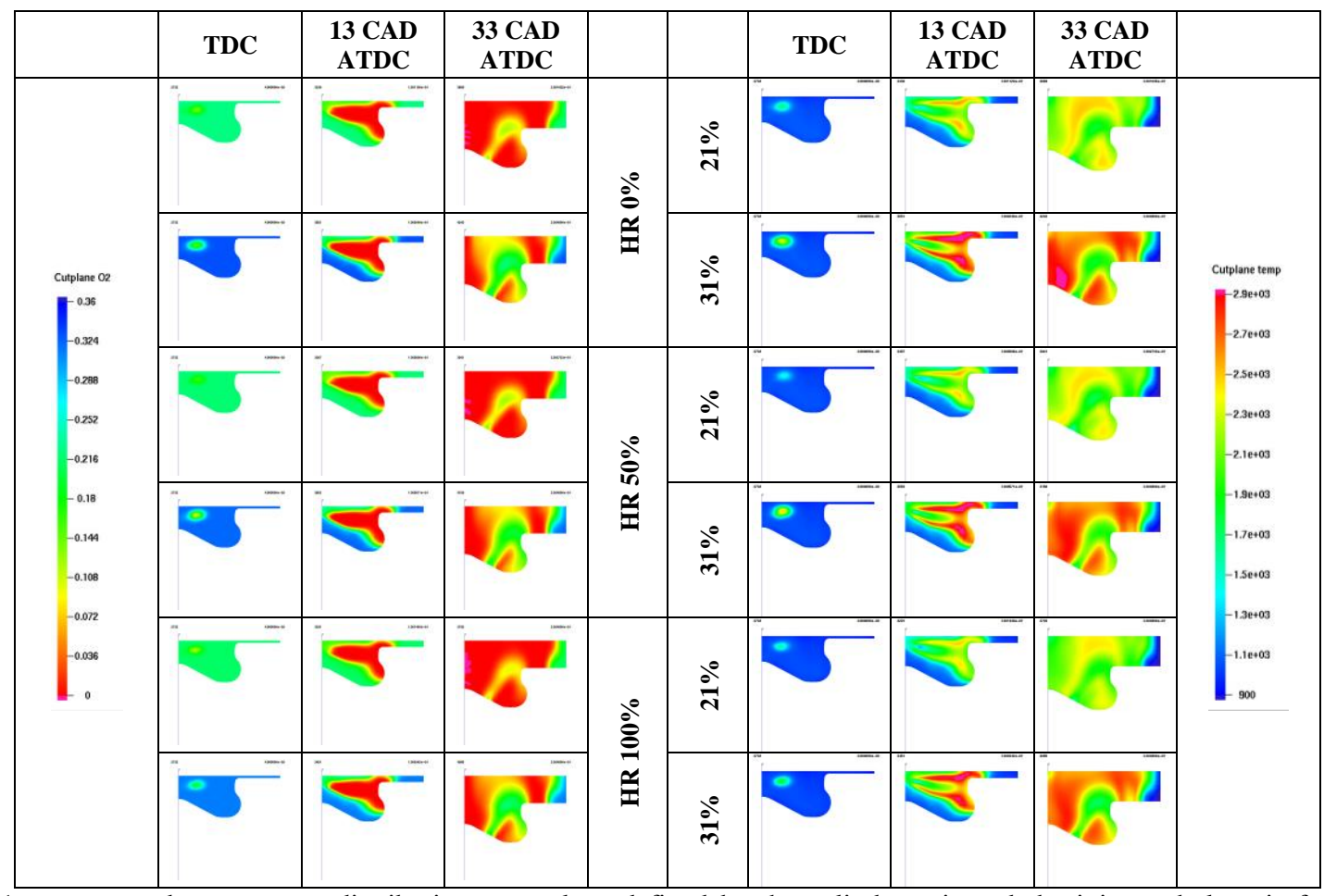

Figure A1: oxygen and temperature distribution on a plane defined by the cylinder axis and the injector hole axis for different Humidity Ratio (HR), base injection profile

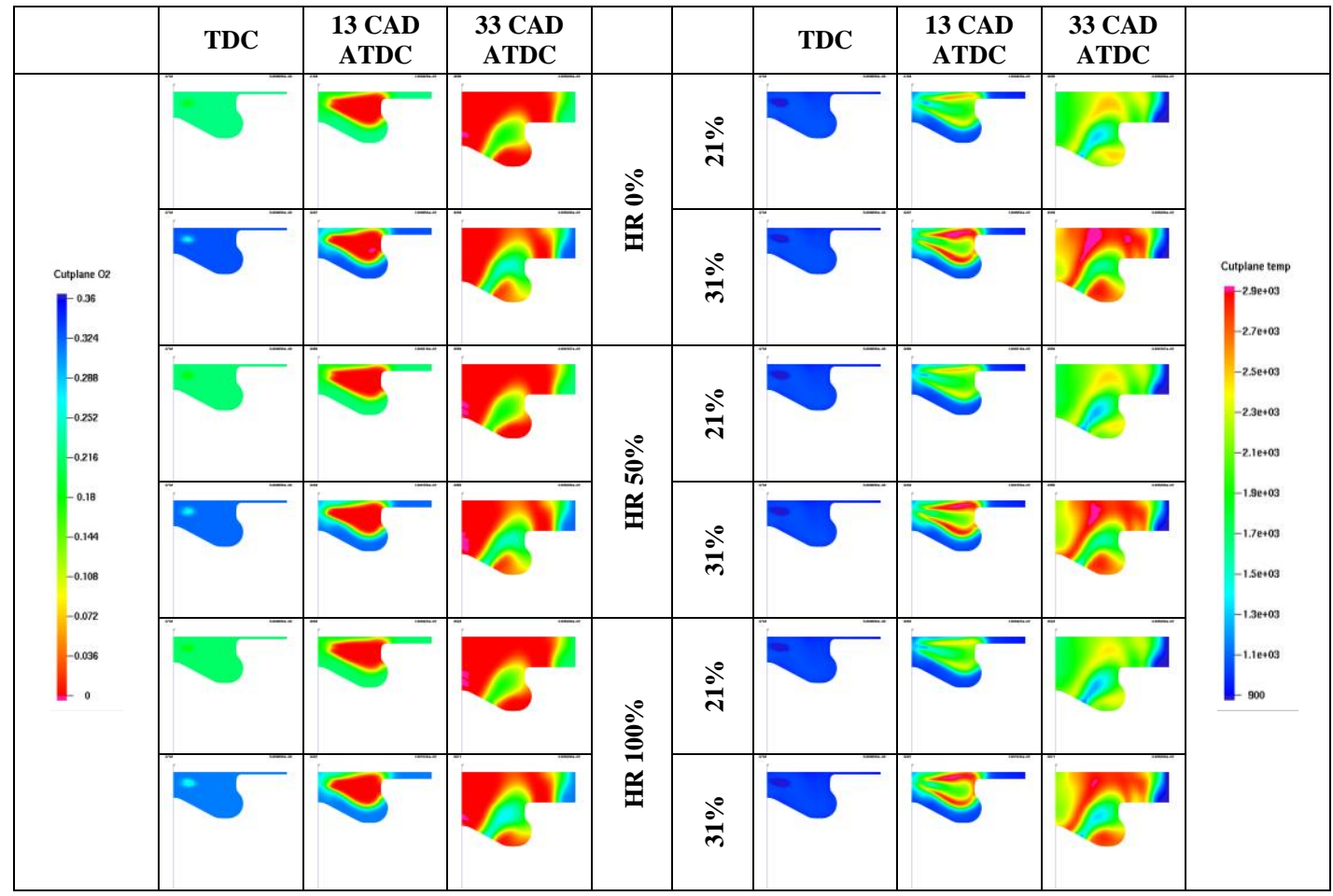

Figure A2: oxygen and temperature distribution on a plane defined by the cylinder axis and the injector hole axis for different Humidity Ratio (HR), injection profile delayed od 4 cad (SOI: +4 cad) 


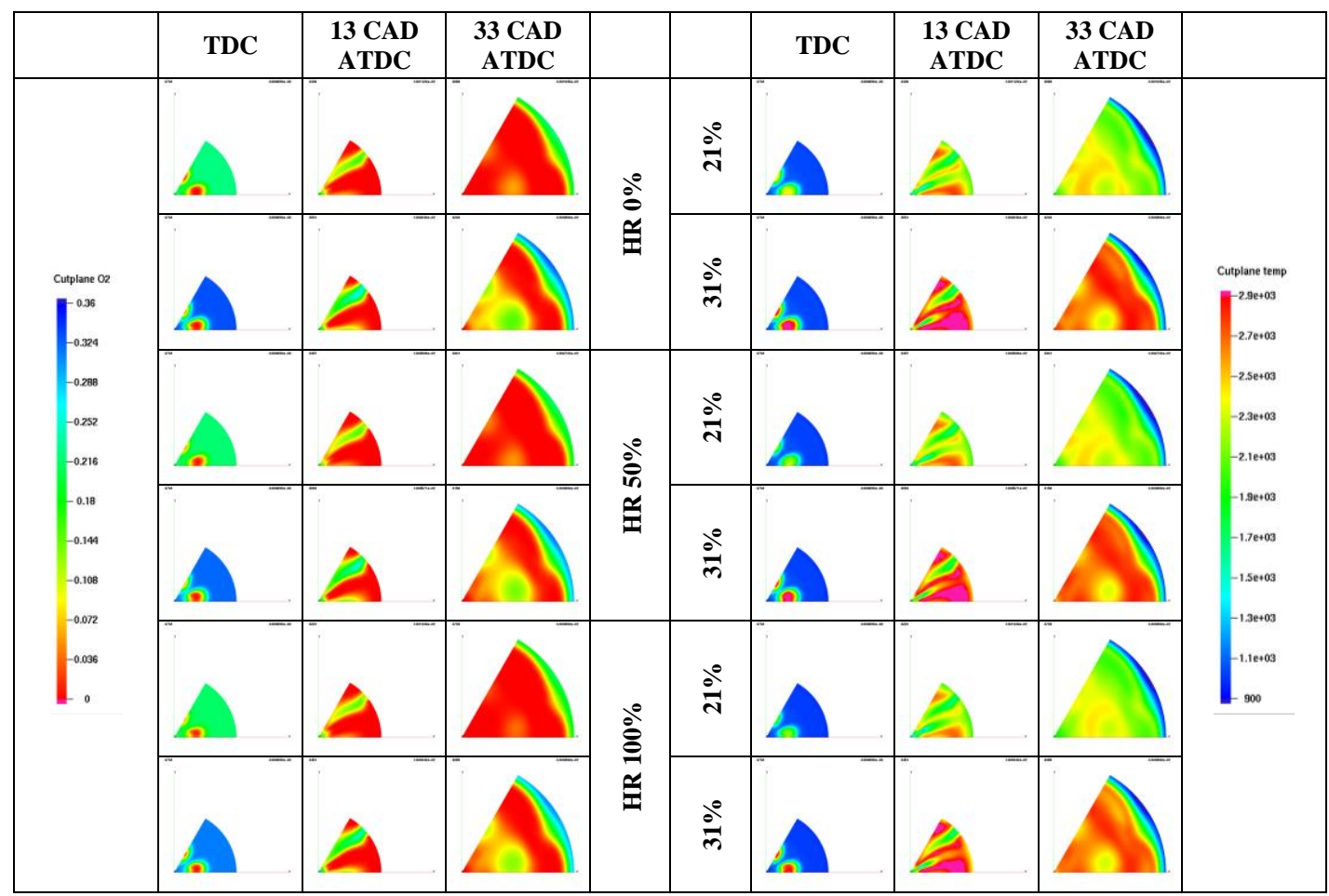

Figure A3: oxygen and temperature distribution on a plane perpendicular to the cylinder axis and passing through the centre of the injector hole for different Humidity Ratio (HR), base injection profile

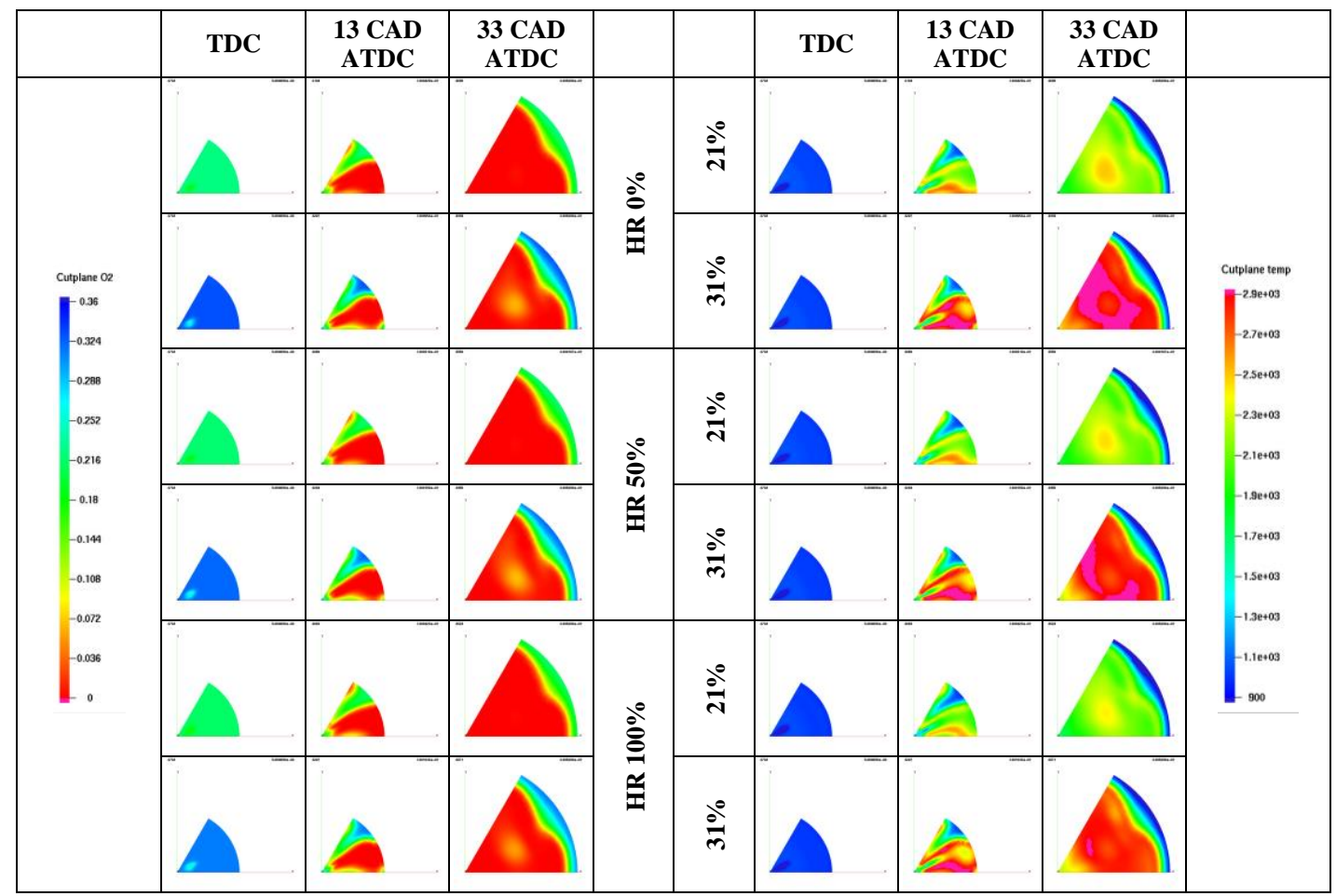

Figure A4: oxygen and temperature distribution on a plane perpendicular to the cylinder axis and passing through the centre of the injector hole for different Humidity Ratio (HR), injection profile delayed od 4 cad (SOI: +4 cad) 